\section{㩆郭 RMA \\ Antropología Social}

\title{
Forma y variación en la estructura de aldea balinesa
}

de Clifford Geertz

Traducción: Andrea Novello (Carrera de Antropología, Facultad de Filosofía y

Letras, Universidad Nacional de Córdoba)

Corrección: Carolina Mosconi (IDACOR-CONICET, Museo de Antropología,

Facultad de Filosofía y Letras, Universidad Nacional de Córdoba)

Revisión: Ezequiel Grisendi IDACOR-CONICET, Museo de Antropología, Facultad

de Filosofía y Letras, Universidad Nacional de Córdoba)

El texto originalmente apareció bajo el título "Form and variation in a balinese village structure", en American Anthropologist, New Series, Vol. 61, Nº (Diciembre de 1959), pp. 991-1012. Agradecemos a American Anthropologist por la autorización a publicar esta traducción. Elegimos traducir y editar este texto de Clifford Geertz en la RMA, por considerarlo una pieza clave para los debates de la "era estructuralista", por sus cualidades intrínsecas y su trascendencia para la teoría - etnografía, asi como por tratarse de un texto primario de un autor fundamental.

Como todo lo balinés, las aldeas son peculiares, complicadas y extraordinariamente diversas. No se encuentra uniformidad en la estructura social a lo largo del pequeño y muy poblado territorio, ni una forma evidente de organización aldeana que sea fácilmente retratada en términos de una construcción tipológica singular. No existe una aldea "promedio" cuya descripción pueda caracterizar la totalidad. Más bien la aldea balinesa se configura como un conjunto de sistemas sociales maravillosamente complejos, donde ninguno se asemeja entre sí, donde ninguno carece de alguna notable peculiaridad en su forma. Incluso las aldeas contiguas pueden organizarse de modos diversos; elementos formales -como la casta o el parentesco- de importancia central en una aldea, pueden ser de significación marginal en otra. Cada una de las aproximadamente veinticinco aldeas que se analizaron en 1957 en las regiones de Tabanan y Klungkung, en el sur de Bali -un área total de tan solo $1.165 \mathrm{~km} 2-$ revelaron características estructurales significativas en algún sentido idiosincrático. ${ }^{1} \mathrm{Ni}$ la simplicidad ni la uniformidad son virtudes balinesas.

Aun así todos estos sistemas sociales de pequeña escala pertenecen, sin dudas, a una familia. Representan variaciones, intrincadas por cierto, de un conjunto común

\footnotetext{
El trabajo de campo sobre el que se basa este estudio se llevó a cabo desde Agosto de 1955 hasta Julio de 1958, con una pausa de tres meses desde Enero hasta Marzo de 1958. Conté para ello con una beca de la sección de ciencias sociales de la Fundación Rockfeller, administrada por el Centro de Estudios Internacionales, Instituto de Tecnología de Massachusetts (M.I.T.) Estoy en deuda con mi asistente de investigación E. Rukasah, de la Fakultas Pertanian en Bogor, Indonesia, y con mi esposa Hildred Geertz por sus significativas contribuciones a este estudio. Este texto fue escrito durante una pasantía en el Centro de Estudios Avanzados en Ciencias del Comportamiento, y deseo agradecer a muchos de mis colegas de ese Centro por sus críticas y comentarios sobre los primeros borradores. Para vistas generales de la cultura balinesa, ver Bateson y Mead (1942), Covarrubias (1936) y Korn (1936).
}

de temas organizacionales. Lo que es constante en la estructura de la aldea balinesa no es la estructura en sí, sino el conjunto de componentes a partir del cual se edifica. Estos componentes son en sí mismos discretos, más o menos independientes entre sí: la aldea balinesa no es, en modo alguno, una unidad territorial corporativa, que coordina todos los aspectos de la vida en términos de residencia y propiedad de la tierra -como han sido comúnmente descritas las aldeas campesinas-, sino una composición de estructuras sociales, cada una basada en un principio diferente de afiliación social y articuladas entre sí, sólo en la medida en que parece esencial. Es precisamente este carácter múltiple y complejo, propio de la estructura de la aldea balinesa, lo que posibilita alcanzar una importante variación, y mantener, a su vez, una caracterización formal y general, ya que este juego entre las formas estructurales discretas es lo suficientemente significativo como para permitir un amplio rango de elecciones referidas al modo de integración entre sí, en cualquier instancia particular. Al igual que muchos compuestos orgánicos integrados por las mismas moléculas dispuestas en diferentes configuraciones, las aldeas balinesas exhiben una amplia variación en la estructura, sobre la base de un conjunto de ingredientes invariables fundamentales.

Quizás la mejor manera de comprender sistemáticamente esta estructura aldeana sea conceptualizarla en términos de una intersección de planos de organización social teóricamente separables. Cada plano consta de un conjunto de instituciones sociales basadas en un principio de afiliación completamente diferente, en una manera distinta de agrupar o separar individuos. En cada aldea en particular todos los planos importantes estarán presentes, pero la manera en que se adaptan entre sí, la manera en que se entrecruzan, diferirá, ya que no hay un principio claro sobre el cual debe formarse esta intersección. Es así 
que el análisis de la estructura de la aldea consiste, en primer lugar, en discriminar los planos organizacionales de significación, y luego, en describir la manera en que en efecto éstos se entrecruzan.

En Bali, los siete planos de mayor relevancia se organizan a partir de: (1) la obligación compartida de adoración en un templo determinado, (2) la residencia común, (3) la propiedad de tierras para el cultivo de arroz situadas en una misma cuenca fluvial, (4) la comunalidad de casta o estatus social atribuido, (5) los lazos de parentesco consanguíneos y políticos, (6) la pertenencia común a alguna organización "voluntaria", y (7) la subordinación legal a un solo funcionario administrativo gubernamental. En el presente trabajo, analizaré primero cada uno de estos planos de organización, luego describiré tres aldeas como ejemplos de modos diversos en que estos planos se entrecruzan, y finalmente ofreceré una discusión sobre algunas de las implicancias teóricas de este tipo de organización de aldeas.

\section{PLANOS DE ORGANIZACION SOCIAL}

1. Obligación compartida de adoración en un determinado templo

Bali es una tierra de templos. Uno los ve por doquier -bajo el árbol baniano de la aldea, entre los arrozales, junto a las cascadas, en el centro de las grandes ciudades, cerca de los cementerios, en la costa marítima, en islas lacustres, en el patio de cada casa, en la cima de las montañas- en todas partes; de todos los tamaños y en diferentes estados de reparación; todos, o la mayoría, muestran la forma tradicional: las altos muros de ladrillo, las verjas intrincadamente talladas, los altares al estilo pagoda con sus techos de paja. ${ }^{2}$ No hay ruinas en Bali: cada uno de estos millares de templos cuenta con un sacerdote hereditario y una congregación definida de adoradores obligados a realizar actividades rituales dentro de los confines de sus muros en intervalos regulares, comúnmente cada seis meses. Tal congregación es llamada a njungsung el templo -literalmente, a cargar el templo sobre sus cabezas, de la misma forma en que las mujeres cargan prácticamente todo en Bali, incluso las elaboradas ofrendas que llevan a los templos durante los días festivos. ${ }^{3}$ Cada familia en Bali, a menos que sea cristiana o musulmana, tiene al menos media docena de estos templos -llamados pura- en su haber.

De la gran variedad de pura, los más importantes para los balineses son, por lejos, los Kahyangan-Tiga. Kahyangan es la palabra honorífica que designa templo (literalmente "lugar de los dioses"), y comprende un pura de inusual importancia; tiga significa tres, por lo tanto, "los tres grandes templos". Existen probablemente más de mil

\footnotetext{
2 Para una descripción más detallada de las formas de los templos balineses, ver Covarrubias (1936).

3 Un festival de templo balinés es descripto en detalle en Belo (1953).
}

conjuntos de dichos templos en Bali, con un rango de afiliación que se extiende desde las cincuenta hasta varios miles de familias. Estos tres templos que se hallan en cualquier localidad son los Pura Puseh, o templo del origen, teóricamente el templo construido en el primer asentamiento en el área; los Pura Dalam, o templo del cementerio para los espíritus de los muertos locales, y los Pura Balai Agung, o "templo del gran consejo" (de los dioses), destinado principalmente a mantener la fertilidad de los arrozales circundantes. En el caso de los dos primeros templos, los festivales se celebran una vez cada 210 días -año balinés-; en el caso del tercero, una vez durante el año lunar; los días específicos dependen de la tradición de cada templo. Durante estas festividades, se cree que los dioses descienden desde el cielo, permanecen por tres días, y luego regresan a su hogar; la congregación está obligada a entretenerlos durante su estadía, a través de complejas ofrendas, elaborados rituales y hábiles actuaciones artísticas, bajo la dirección general del sacerdote y del jefe secular del templo. El costo de los festivales, la gran cantidad de trabajo invertido y el mantenimiento general de los templos recae por igual sobre cada miembro de la congregación, organizándose de manera muy complicada para cumplimentar tales fines. Como ya se mencionó, la pertenencia a los KahyanganTiga se define territorialmente, a cada balinés le corresponde solo uno de estos conjuntos. Sin embargo, uno no puede decir, como ha sido sostenido, que pertenece al templo de su "aldea", y por lo tanto, que Kahyangan- Tiga puede traducirse como "los templos de las tres aldeas", ya que solo en casos específicos se dan en los confines de la unidad política territorial básica, que aquí se denominan "caseríos", o cercanos a las congregaciones Kahyangan-Tiga colindantes; en la mayoría de los casos, las unidades religiosas y políticas no están coordinadas sino que se entrecruzan. Sea cual fuera la aldea balinesa, no se la puede definir en función de los adoradores de un conjunto de Kahyangan-Tiga, ya que la gente obligada a adorar de esta manera, por lo general no conforma un grupo que desempeñe otras funciones sociales-políticas, económicas, familiares, etc. La congregación de la Kahyangan-Tiga es, en esencia, un cuerpo religioso específico; en la mayoría de los casos se congregan únicamente para los festivales obligatorios. ${ }^{4}$ Así, los repetidos y muy queridos ritos en estos templos cumplen el rol de formar un lazo fundamental entre los balineses que habitan el sector rural de un territorio más amplio. Pese a que este lazo vaya en contra de otros vínculos formados a partir de actividades sociales más concretas, como es típico de los lazos religiosos, termina por reforzarlos.

\footnotetext{
4 Es también una comunidad legal en la que todas las personas de una misma congregación Kahyangan-Tiga siguen las mismas reglas generales relacionadas con la pertenencia del caserío, el matrimonio, la herencia, el trabajo cooperativo, etc, reglas que difieren en detalle de un grupo Kahyangan-Tiga a otro. Algunas veces esta comunidad legal está dirigida por un Bendesa Adat, o jefe del derecho consuetudinario, que da consejos y directivas en problemas tradicionales. Pero, nuevamente, es solo en el extraño caso de que esta comunidad legal coincida con una comunidad política concreta.
} 
Aparte de los Kahyangan-Tiga hay docenas de otros tipos de templos, con bases diferentes sobre las cuales se constituyen sus congregaciones: están los templos de los arrozales, a los que concurren los hombres que poseen tierra dentro de una sociedad de riego particular; los templos de parentesco, conformado por miembros de una sola rama patrilineal; los templos de castas donde únicamente adoran los que poseen un determinado rango; están los templos de asociación formados voluntariamente entre compañeros, donde las obligaciones se heredan mediante descendencia; los templos estatales asistidos por súbditos de un solo señor, y así sucesivamente. Nuevamente, algunos de estos corresponden a grupos sociales concretos con propósitos religiosos, otros no; algunos son fáciles de encontrar, otros no; algunos establecen obligatoriedad para todos sus miembros, otros son voluntarios. Así, al trazar los tipos de templos en una región, se puede trazar la forma general de la estructura social local, aunque no sus características distintivas. El sistema de templos de la campiña balinesa se constituye en una suerte de molde relativamente firme en función del cual la organización social rural se expresa, y los festivales semi anuales de cada templo dramatizan los tipos de lazos a partir de los cuales los campesinos balineses construyen su vida colectiva. Sin embargo, este sistema no define a la vida en algo simple o invariable, ya que dentro del molde general, las posibilidades de variación referidas a la tensión, la combinación y la adaptación de los elementos sociales parecen prácticamente ilimitadas.

\section{Residencia común}

Como ocurre con la mayoría de los indonesios, las viviendas de los balineses se distribuyen en un patrón de asentamiento agrupado, sus casas-recinto amuralladas se apiñan entre sí al mejor estilo urbano, con el fin de preservar los arrozales, ante una población tremendamente densa y en crecimiento. ${ }^{5}$ Entre tales agrupamientos la unidad política territorial básica es el caserío, o band jar. Un Bandjar, que, según el tamaño del asentamiento puede o no estar aislado espacialmente, contiene entre una docena hasta cientos de familias nucleares, con un promedio quizás de ochenta o noventa. En la mayor parte de Bali, el bandjar puede definirse sencillamente como el conjunto de individuos que se encuentra sujeto a las decisiones tomadas en una casa de reunión del caserío, o balé banjar. Las reuniones de bandjar integradas por todos los hombres jefes de familia normalmente se celebran en este balé cada 35 días, equivalente al mes balinés. En esta instancia, se debaten y formulan políticas decisivas para toda la unidad corporativa que supone el bandjar, principalmente

\footnotetext{
5 En 1954, la población total de Bali se estimó en 1.500.000 habitantes, con una densidad media de alrededor de 700 habitantes por milla cuadrada. En las áreas densamente pobladas del sur de Bali la densidad alcanza cerca de 1.500 habitantes por milla cuadrada. (Raka 1955).
}

mediante un proceso de consenso universal que gobierna el "sentido de la reunión". De la misma forma que el templo es el centro de la comunidad religiosa, la casa de reunión -una estructura sin paredes, con techo puntiagudo y estructura de aspecto polinesio usualmente ubicada en el centro del caserío- constituye el centro de la comunidad política. ${ }^{6}$

Las funciones que se le asignan al bandjar son aquellas legales-gubernamentales que tienen en común las comunidades campesinas de casi todo el mundo. Tiene a cargo la seguridad local, la legitimación del matrimonio y el divorcio, la resolución de conflictos sucesorios, y el mantenimiento de las obras públicas como los caminos rurales, la casa de reunión, la estructura material que sustenta el mercado local y el reñidero de gallos. Comúnmente posee una orquesta gamelán y posiblemente trajes de baile y máscaras. Como sucede en muchas, aunque no en todas las partes de Bali, los terrenos para vivienda conforman una unidad colectiva perteneciente al bandjar; el caserío también puede regular la distribución de las viviendas y controlar asimismo la inmigración. Puede incluso expulsar a miembros que hayan cometido delitos graves, confiscar sus tierras y negarles todo derecho político, lo que para los balineses representa la más severa de las sanciones sociales.

El caserío también ejerce importantes poderes impositivos y fiscales. Tiene la facultad de multar a las personas por infracciones contra las costumbres locales, exigir - casi con libertad-contribuciones al servicio del entretenimiento público, de la reparación de estructuras cívicas o de actividades de bienestar social. Tiene asimismo la facultad de ejercer el derecho de apropiarse de la cosecha de los arrozales pertenecientes a los miembros del bandjar - que obran como recolectores - a cambio de una participación consuetudinaria del producto. Consecuentemente, la mayoría de los bandjar tienen tesoros considerables e incluso pueden ser propietarios de arrozales, adquiridos con ingresos, y cuyas recaudaciones también se hallan destinadas a propósitos públicos. Hoy en día, algunos bandjar son incluso dueños de camiones o colectivos, otros ayudan a financiar las escuelas locales y otros erigen cafeterías cooperativas.

Finalmente, el bandjar también cumple el rol de grupo de trabajo comunal para ciertos propósitos rituales, especialmente en cremaciones, que junto con los festivales del templo, siguen siendo las ceremonias más importantes de Bali, pese a que su tamaño y frecuencia se ha visto reducido en alguna medida desde la guerra. ${ }^{7}$ Cuando una familia decide llevar a cabo una cremación, todos los miembros del bandjar están obligados a realizar contribuciones en especie y preparar las ofrendas, la

\footnotetext{
6 En el área de Tabanan, los balé están ausentes en la mayoría de los caseríos, por lo que las reuniones se celebran al aire libre bajo un árbol baniano o en el patio del templo.

7 Para descripciones de estas ceremonias, ver Covarrubias (1936).
} 
comida y la parafernalia hasta con un mes de anticipación. Cooperación similar, en menor grado, habitualmente se requiere para otros ritos de paso o transición, tales como erupción dental, el matrimonio o la muerte. El bandjar es, paralelamente, una unidad legal, fiscal y ceremonial, que proporciona quizás el espacio más intensamente valorado para expresar la solidaridad campesina.

Las cabezas de los caseríos se denominan klian, literalmente "anciano". En algunos bandjar hay más de uno, por lo general, dos o tres. Algunas veces hay cuatro o cinco, lo que comúnmente indica que es un bandjar extenso o uno claramente segmentado en un fuerte linaje u otros subgrupos, dentro de los cuales se le asignan, a todas las minorías transversales significativas, roles particulares en la dirección del bandjar. Actualmente los klian se eligen cada cinco años y luego son reemplazados por un grupo nuevo, generalmente elegido por el grupo saliente y con la aprobación de la reunión de bandjar, con el fin de evitar el electoralismo. Los klian son asistidos por varios funcionarios de menor rango, cuyo trabajo por lo general se rota mensualmente entre los miembros del bandjar. Aunque el klian preside las discusiones en la reunión del bandjar, atesora la hacienda pública, dirige el trabajo comunal y ejerce cierta influencia en la comunidad local, no posee demasiada autoridad formal. En línea con la tendencia general balinesa de dispersar el poder muy finamente, de mostrar antipatía y desconfianza hacia quienes se proyectan por encima del grupo, y de ser particularmente celoso de los derechos del público como grupo corporativo, los klian, en un sentido muy literal, sirven más fielmente al bandjar que sus maestros, y la mayoría es extremadamente cautelosa al proceder sin la aprobación dispuesta en la reunión de caserío. Los klian, que no son retribuidos económicamente y ni tienen gratificaciones especiales, sienten que su posición conlleva la obligación de trabajar más arduamente para la comunidad; con cansancio comparan su trabajo con el del encargado del cuidado de los patos: como el pato, el bandjar emite un montón de graznidos, pero no da ningún huevo.

3. Propiedad de las tierras para el cultivo de arroz situadas en una misma cuenca.

A diferencia de las sociedades campesinas en la mayor parte del mundo, en Bali prácticamente no hay conexión entre la propiedad y la gestión de las tierras cultivables por un lado, y la organización política local (es decir, el caserío) por otro. La sociedad de riego o subak, regula todos los asuntos relacionados con el cultivo del arroz húmedo y constituye una organización completamente independiente del bandjar. "Tenemos dos clases de costumbres", dice el balinés, "costumbres secas para el caserío, y costumbres húmedas para la sociedad de riego". Los subak se organizan conforme el sistema hídrico: todos los individuos que poseen tierras irrigadas a partir de una misma fuente hídrica -mismo dique y canal que se extiende desde la presa hasta los campos- pertenecen a un mismo subak. Los subak, cuyas fuentes de agua están compuestas por ramificaciones que nacen de una represa mayor, forman unidades más grandes y menos interrelacionadas; finalmente toda la cuenca de un mismo sistema fluvial forma una unidad completa e incluso más flexiblemente integradora. Como la propiedad de la tierra en Bali está bastante fragmentada -la adquisición por individuo típicamente consiste de parcelas de dos o tres cuartas partes o media hectárea, distribuidas por la región, en general a cierta distancia de su casa-, los miembros de un subak casi nunca responden un caserío, sino a diez o quince. Desde el punto de vista del caserío, los miembros de un solo bandjar suelen poseer tierra en numerosos subak. Así, como la distribución espacial de los templos establece los límites de la organización religiosa balinesa, y el patrón de asentamiento nucleado forma el marco físico para la organización política, el esquema concreto del sistema de irrigación balinés de simples represas de piedra y arcilla, canales y túneles de barro y compuertas de bambú proveen el contexto en el cual se organizan las actividades agrícolas balinesas.

Aunque los detalles y terminología organizacionales difieren ampliamente entre las regiones, existen jefes electos -usualmente llamados klian subak -en contraposición al klian del bandjar- para la administración del subak, mientras que la organización superior del sistema fluvial y de cuencas está coordinada por funcionarios designados por el gobierno central como los herederos de la irrigación tradicional, y funcionarios fiscales de los antiguos reinos de Bali. Sin embargo, y una vez más, es el subak quien determina, a la luz de tradiciones heredadas, sus propias políticas.

El subak es responsable de la manutención de su sistema de riego, una tarea que implica un trabajo casi continuo, para la distribución de agua entre los miembros del subak y para la planificación de la siembra. Impone multas por infracción a las reglas (robar agua, ignorar las directivas de siembra, eludir el trabajo, entre otras), mantiene los templos del subak y lleva adelante toda una secuencia de actividades rituales conectadas con el ciclo agrícola, controla la pesca, la recolección de forraje, la crianza de patos y otras actividades secundarias del subak. En la mayoría de los subak más importantes de la actualidad, el verdadero trabajo de irrigación -la reparación constante de las presas y canales, y la apertura y el cierre permanente de las compuertas que permiten la distribución del agua - se lleva a cabo solo por una parte de los miembros del subak, denominados "el grupo de agua", que luego reciben un pago de dinero por aquellos no tan trabajadores, monto determinado por el propio subak. Complican este panorama, los complejos patrones de tenencia compartida, los sistemas de rotación de cultivos controlados, los modos diversos de organización interna del subak, y los intentos por parte de los funcionarios gubernamentales para mejorar la coordinación entre 
los subak. Pese a esto, el estatus del subak como grupo independiente, autorregulado, corporativo y con reglas y propósitos propios sigue siendo indiscutible hoy en día como lo era en los tiempos de los reyes balineses.

\section{Comunalidad de estatus social atribuido}

Por lo general, a los balineses, como a los hindúes y de quienes han tomado (y reformulado) tanto, se los describe a partir de un sistema de castas. $Y$ en efecto es así, teniendo en cuenta que el estatus social se hereda patrilinealmente, que el matrimonio se regula en términos de estatus y que, salvo en pocos casos, la movilidad dentro del sistema de prestigio es en teoría imposible, y en la práctica, un tanto difícil. Sin embargo, este sistema de casta no resulta tan inherente visto desde el sentido de poseer una jerarquía de grupos corporativos bien definidos, cada uno con roles ocupacionales, sociales y religiosos específicos y exclusivos, respaldados por patrones ceremoniales de elusión y comensalidad, y por un complejo sistema de creencias que justifica la inequidad radical del estatus. Si el término "casta" no estuviera tan profundamente arraigado en la literatura de Bali, podría ser menos confuso referirse al sistema balinés como uno definido por "títulos", ya que es en función de un conjunto de títulos explícitos -que pasa de padres a niños y están ligados al nombre del individuo como fórmulas de tratamiento y referencia-, que el prestigio se distribuye.

Siguiendo el estilo hindú, los balineses se dividen en cuatro grupos principales: Brahmana, Satria, Vesia, y Sudra. Ya que más del 90 por ciento de la población se ubica dentro los parámetros de la cuarta categoría, se adopta una división más cotidiana y que distingue a los Triwangsa ("las tres personas"), los primeros tres grupos tomados como una unidad, y los Sudra, que de alguna manera más amplia aunque no del todo coherente corresponde a la distinción entre burguesía-campesinado afín a las civilizaciones no industriales en general. Cada grupo se subdivide en relación con el sistema de títulos, la base real de la posición del individuo en la sociedad. Ante una lista cualquiera de títulos - Ida Bagus, Tjokorda, Dewa, Ngakan, Bagus, I Gusti, Gusti, Gusi, Djero, Gdecualquier balinés, incluso el más desinformado, podría decir que se muestran en orden de estatus descendente, pero solo una pequeña minoría de teóricos podrían decir que el primero pertenece al título de Brahmana, los cuatro siguientes a Satria, los tres posteriores a Vesia, y los dos últimos a Sudra. ${ }^{8}$ Al distinguir tipos de estatus, los hombres piensan y hablan en términos de títulos, no de casta.

En general, un hombre puede casarse con cualquiera

\footnotetext{
8 Sólo una minoría Sudra, considerada de tener mayor prestigio que la masa por sus antiguos lazos de afinidad o políticos con los grupos de estatus superior, tienen verdaderos títulos de residencia y referencia. La mayoría Sudra no tiene títulos de residencia en absoluto.
}

del mismo título o menor, una mujer con alguien del mismo título o superior dando lugar - por lo tanto- a la hipergamia. En los tiempos anteriores a los holandeses (es decir, antes de 1906, ya que el Sur de Bali quedó bajo control directo de Holanda a principio de este siglo), los matrimonios entre castas se castigaban con el destierro o la muerte, -particularmente en el caso de una mujer Triwangsa y un hombre Sudra. Incluso hoy una mujer que se casa con alguien de una casta inferior es comúnmente "abandonada" por su familia, es decir, no es más reconocida como pariente y cesan las relaciones sociales entre ella y sus padres. No obstante, en la actualidad, tales violaciones a menudo sanan con el trascurso de los años, particularmente si la brecha social no es tan amplia; sin embargo los matrimonios entre castas son, en cualquier caso, muy raros incluso al día de hoy.

Debido a que la cantidad de Triwangsa es mucho menor que la de Sudra, la regulación del estatus a través del matrimonio supone que los patrones de parentesco político tienden a establecerse de manera diferente para ambos grupos, ya que la mayoría de los matrimonios Triwangsa son exógamos en relación con el caserío, es decir, interlocales, mientras que la mayoría de los matrimonios Sudra son endógamos, es decir, intralocales. Este contraste eleva al grupo Triwangsa, horizontalmente vinculado, como un grupo supra-caserío de Bali, por encima del grupo Sudra, fuertemente localizado; un patrón congruente, por supuesto, con el hecho de que los Triwangsa monopolizaron, casi por completo, los roles políticos y religiosos interlocales y de orden superior de la estructura estatal tradicional balinesa, como en el caso de la actual rama balinesa del servicio civil indonesio.

La composición de casta (o título) de cualquier caserío (grupo de templo o sociedad de riego) varía ampliamente. En una localidad uno puede encontrar representantes de un amplio rango de títulos en una gradiente suave entre los superiores y los inferiores, en otra solo aquellos muy superiores o muy inferiores, en otra solo rangos medios o superiores, en otra únicamente los Sudra, y así sucesivamente. $Y$, como la casta es un factor crucial en la organización política y de parentesco, tal diversidad comprende diferencias significativas en la estructura social. La estratificación del prestigio en Bali supone una poderosa fuerza integradora en ambos niveles, tanto en el local como a nivel de la isla.

\section{Parentesco consanguíneo y político}

En Bali, la ascendencia y la herencia son patrilineales; la residencia es virilocal pese a que la terminología de parentesco es clásicamente hawaiiana -es decir, íntegramente bilateral y generacional. La principal excepción a la descendencia patrilineal y a la residencia consiste en que el hombre sin hijos puede casarse con una hija uxorilocalmente y designarla como heredera; el marido renuncia a los derechos heredados por línea 
paterna - como lo hace una mujer comúnmente al contraer matrimonio-, y se va a vivir a la casa de su esposa. Ya que esto ocurre por lo general en circunstancias en las que no se cuenta con herederos masculinos, las genealogías balinesas muestran un elemento ambilineal notable, en el que cierto porcentaje de los lazos se trazan a través de mujeres y no de hombres.

La unidad residencial básica es el pekarangan o recinto amurallado que, en términos de parentesco, puede albergar grupos que van desde una simple familia nuclear hasta una familia extendida patrilineal de tres o más generaciones. Usualmente dos o tres familias nucleares, a menudo con solteros o parientes mayores patrilineales, ocupan un solo pekarangan. No obstante, no es inusual encontrar a diez o quince familias, emparentadas mediante un abuelo paterno en común, particularmente entre los grupos de castas superiores. Además de ser una unidad residencial, el recinto integra una unidad religiosa muy importante, debido a que cada grupo mantiene un pequeño templo en la esquina noreste del patio, dedicado a antecesores directos y en el cual se celebran ceremonias dos veces al año. Por lo general, este recinto se divide en cocinas, llamadas kuren, una por cada familia nuclear, aunque a veces puedan ser dos o tres; es precisamente este grupo que conforma la unidad de parentesco básica desde el punto de vista de todos las instituciones sociales superiores: es el kuren el que tributa a los templos Kahyangan-Tiga; al que se le concede un lugar en la casa de reunión; el que debe enviar un trabajador para reparar la represa o participar de la cosecha; es la unidad de propiedad de los arrozales, y así sucesivamente.

Dentro de cualquier caserío y por encima del recinto y de la cocina, comúnmente se encuentra de uno a diez grupos endogámicos de parentesco corporativo, llamados dadia ${ }^{9}$. Tales dadia son básicamente unidades rituales, aunque también pueden cumplir la función de grupos de trabajo colectivo para diversas tareas sociales y económicas; pueden además proveer el marco principal para las interacciones sociales informales con miembros fuera del ámbito familiar inmediato; pueden desempeñarse como una unidad indivisible en la jerarquía de estratificación social; y puede formar una facción bien integrada dentro del sistema político general del caserío. La importancia que asume en estas funciones sociales generales difiere ampliamente de aldea a aldea. En algunas aldeas, la organización de la dadia es el foco central de la vida social, el eje alrededor del cual gira la misma; en otras adquiere relativa importancia secundaria; y en otras pocas, especialmente aquellas semi-urbanizadas, la dadia ni siquiera existe.

\footnotetext{
9 En la mayoría de las aldeas balinesas, el matrimonio preferencial se realiza dentro de la dadia y, si es posible, con la hija del hermano del padre.
}

Raramente la población entera del caserío se organiza en términos de dadia; a veces lo hace solo una minoría definida. Esto se debe a la manera en la que se forman las dadia. Cuando una línea familiar comienza a crecer en tamaño, riquezas y poder político local, comienza a sentir, como consecuencia de lo que es, probablemente, el valor social central balinés, un orgullo de estatus, una necesidad de expresión pública más intensificada. En este momento las diversas unidades familiares que componen la línea se agrupan bajo la representación de un jefe elegido entre ellos a los fines de construir un templo ancestral mayor. Este templo se construye, por lo general, en tierras públicas de propiedad del caserío, y no dentro de los confines de alguna de las unidades familiares, simbolizando así el hecho de que la línea ha alcanzado importancia tanto en el dominio jurídico-político como en el doméstico. Las ceremonias semianuales de adoración a los ancestros se tornan ahora más elaboradas, como lo es la construcción (debido a que el grupo sigue aumentando su poder, tamaño y riqueza) y la renovación periódica del templo mismo, alcanzados todos por una rivalidad de estatus que se palpita con otras dadia locales.

A menudo, entre las dadia más grandes, los subgrupos se dividen en grupos corporativos por propio derecho. Estos sub-dadia (los balineses los diferencian con variados términos) se integran por miembros de la dadia más estrechamente relacionados entre sí, es decir que no todos los miembros de la dadia participan necesariamente en alguna. Algunas veces la mayoría permanece como miembro libre de la dadia sin mantener ningún lazo particular con alguna sub-dadia. En una dadia grande, por ejemplo, había cinco sub-dadia con sesenta de las ochenta cocinas en la dadia, mientras que las veinte restantes no pertenecían a ninguna sub-dadia. En efecto, es la dadia, y no la sub-dadia, la que constituye el grupo fundamental, aunque a menudo esta última también adquiere importantes funciones sociales.

Como fue señalado, las funciones específicas asignadas a los grupos de parentesco varían según el lugar y la integración entre estos grupos con otras instituciones sociales se vuelve compleja. Además, el número y tamaño relativo de los grupos de parentesco en un caserío en particular marca una notable diferencia en la manera en que funcionan ambos, los grupos mismos de parentesco y el caserío. Un caserío con, digamos, una dadia grande y cuatro pequeñas, diferirá en tanto en su organización y como en su funcionamiento de una con tres dadia medianas más una o dos pequeñas, o con cinco o seis de tamaño similar. Estas cuestiones no se tratarán en el presente estudio pero es importante aclarar que el parentesco en Bali, más que reducirse a una preocupación de los asuntos principalmente "familiares" como suele ocurrir en muchas sociedades campesinas, supone una importante fuerza organizativa en la sociedad en general, si bien es una entre muchas. 
6. Pertenencia en común en alguna organización voluntaria

El termino balinés para designar cualquier grupo organizado es el de seka; literalmente "ser como uno". Es por ello que el grupo de la gente del caserío se denomina seka bandjar, el grupo de riego se denomina seka subak, y encontramos también seka dadia, seka pura, y así sucesivamente. Pero más allá de estos grupos formales, más o menos obligatorios, hay cientos de organizaciones completamente voluntarias, denominadas simplemente seka, que se dedican a algún u otro propósito específico. Estas atraviesan todas las otras categorías estructurales y se basan, en su totalidad, en los fines funcionales específicos a los cuales se dirigen.

Existen seka para la construcción de viviendas, para los diversos tipos de trabajo agrícola, para el transporte de mercancías al mercado, para la música, la danza y las representaciones teatrales, para el tejido de las esteras, moldeado de cerámica o fabricación de ladrillos, para el canto y la interpretación de la poesía balinesa, para la construcción y el mantenimiento de un templo en una determinada cascada o un bosque sagrado en particular, para la compra y venta de alimentos, de textiles o cigarrillos, y para literalmente docenas de otras tareas. Muchos bandjar tienen seka para propósitos tan específicos como la caza de ardillas de coco o la construcción de simples ruedas de ferris para las celebraciones navideñas. Estas seka voluntarias pueden integrar desde media docena hasta cientos de miembros; pueden durar por varias semanas o años; y los hijos heredan la pertenencia de sus padres. Algunos de ellas acumulan erarios y beneficios considerables que se dividen entre sus miembros, algunos tienen banquetes anuales de celebración, otros incluso prestan sus ganancias a cambio de intereses.

Como la lealtad al seka es un valor de gran importancia en la cultura balinesa, estos grupos voluntarios no son solo organizaciones periféricas sino una parte básica de la vida social balinesa. Prácticamente cada balinés pertenece a tres o cuatro seka privados de este tipo, y las alianzas que se forman en ellos contrarresta aquellas que se dan en los sectores de la estructura social balinesa organizados más formalmente, en la transversal y compleja integración social característica de la isla. Desde un punto de vista, la organización social balinesa en su totalidad puede describirse como un conjunto de seka formal y voluntario que se interrelaciona de diversas maneras.

\section{Subordinación legal común a un funcionario administrativo gubernamental}

Además del caserío, la sociedad de riego y la organización Kahyangan-Tiga del templo, hay otro tipo de unidad territorial a nivel rural que proviene de la organización de la burocracia gubernamental de Indonesia y que alcanza la zona rural balinesa. Dicha unidad es la perbekelan, llamada así porque es presidida por un funcionario llamado Perbekel. Antes de la Revolución el Perbekel era elegido por sus superiores coloniales; a partir de la misma, es elegido por su distrito electoral. Cumple funciones hasta que se jubile o hasta que se geste un movimiento que lo destituya. Permanece siempre como una persona local, en la mayoría de los casos distinguido por sus vecinos solo por tener un poco más de educación (aunque en línea con las tradiciones de la política balinesa, para estas funciones suelen elegirse las personas con títulos más altos). Tiene bajo su cargo entre dos a seis Pengliman, también conocidos como hombres locales; también elegidos, cada uno con su propia bailía dentro del perbekelan. Ambos, Perbekel y Pengliman, son cargos pagos por el Gobierno, aunque no muy bien, según el número de cocinas en el ámbito de su competencia. Como es a través de ellos que las directivas políticas, las exhortaciones propagandísticas y las actividades de bienestar social de la elite política de Djakarta llegan al campesinado y desde los cuales se informan las condiciones locales, constituyen un tipo de servicio civil rural, una burocracia administrativa en miniatura construida a partir de elementos locales.

Como es de esperarse, y salvo en algún caso específico, los límites del perbekalan, arbitrariamente dibujados, no coinciden con los de otra unidad en la sociedad balinesa, pasada o presente; más bien se agrupan entre cuatro a diez caseríos, en lo que parecía lógico para los eficientes administradores holandeses, la delimitación de unidades administrativas eficaces. Como resultado se dan caseríos que no solo pueden no tener lazos tradicionales entre sí, sino que pueden ser tradicionalmente antagonistas, mientras que otros caseríos con vinculación continua y de larga data pueden encontrarse delimitados por los perbekelan. Es así que el perbekel se ubica en una posición más bien anómala, ya que, aunque sus superiores suelen considerarlo como un "jefe de la aldea" y esperan que tenga importantes poderes ejecutivos basados en la tradición, sus electores suelen considerarlo como un empleado del gobierno, consecuentemente no directamente preocupado por los procesos políticos locales, y cuya dirección se concibe en manos del templo, del caserío, de la sociedad de riego, del grupo de parentesco y de los jefes de las organizaciones voluntarias. El Perbekel no gobierna una unidad orgánica, sino una en la que, en su mayoría, se percibe escasa solidaridad interna; aunque el perbekel pueda tener cierto estatus tradicional en el caserío particular dentro del perbekelan, del cual él mismo es un miembro, es poco probable que lo tenga en otras.

A medida que el estado indonesio incrementa sus actividades en un intento por llevar al país a la modernización, el Perbekel se torna cada vez más importante y siente cada vez más la naturaleza incierta de su posición. El grado al que es capaz de afirmar su rol, a asegurar su dominio sobre el liderazgo tradicional 
en los asuntos relacionados con el estado nacional y a hacer del perbekelan una verdadera unidad política, varía según diversos factores: si es enérgico e inteligente, si es descendiente de una familia gobernante local y tradicional, si su perbekelan incluye caseríos que mantengan lazos perdurables entre sí, si dispone de un número de hombres jóvenes instruidos que apoyan y alientan sus esfuerzos "modernizadores", entre otros factores. Al igual que con los otros planos descritos, el papel que cumple la unidad de perbekelan en la estructura social rural balinesa no es describible en términos de un constructo tipológico estático, sino que solo puede delinearse en función de variaciones en torno a un cierto conjunto definido de posibilidades organizacionales.

\section{TRES ALDEAS BALINESAS}

En el análisis de la estructura social rural balinesa, se ha evitado afanosamente referirse al concepto de "aldea", principalmente por ser un concepto utilizado por los balineses en formas variadas y mutuamente contradictorias. En ocasiones, "aldea" (desa, un préstamo lingüístico sánscrito) se utiliza como sinónimo de bandjar (la unidad política rural básica); otras veces para designar a la Kahyangan-Tiga (congregación del templo); algunas veces, especialmente por parte de los residentes urbanos y funcionarios gubernamentales, para referirse a la región circunscripta a un Perbekel; y quizás, más comúnmente, para denominar una región vagamente demarcada en la cual los planos de organización se entrecruzan de manera tal que la gente que vive en la región estrecha mayores lazos entre ellos que con la de regiones adyacentes. A partir de este sentido último y más bien difuso, "aldea" alude a los aspectos integradores en oposición a los aspectos analíticos de la estructura social rural, y es precisamente en este sentido que se utilizará el término aquí. Una aldea no es un caserío, un grupo de templo, o un perbekelan, sino un ejemplo concreto de la intersección de los diversos planos de la organización social en una determinada localidad, delimitada solo en términos generales.

\section{Njalian}

En los tiempos anteriores a la ocupación holandesa constituía la sede de un señor menor y la de un mercado secundario. Njalian se encuentra en el borde occidental del antiguo reino y actual regencia de Kluingkung, y es una de las aldeas de Bali más complejamente organizadas. En Njalian el entrecruzamiento de lealtades alcanza un grado de complejidad casi increíble. El perbekelan de Njalian -el actual Perbekel es el jefe de la casa gobernante tradicional, un Tjokorda por título- tiene unas tres mil cocinas distribuidas entre ocho caseríos, seis contiguas dentro de un gran grupo de asentamientos, y dos separadas por dos o tres kilómetros de distancia. Hay además cuatro agrupaciones de templos Kahyangan-Tiga. A una primera pertenecen los miembros de cuatro de los caseríos contiguos, a una segunda agrupación pertenecen aquellos de un caserío en el grupo principal y de uno de grupos separados, a una tercera agrupación pertenecen únicamente los miembros del otro caserío aislado, y a la cuarta agrupación solo aquellos del otro caserío del grupo principal:

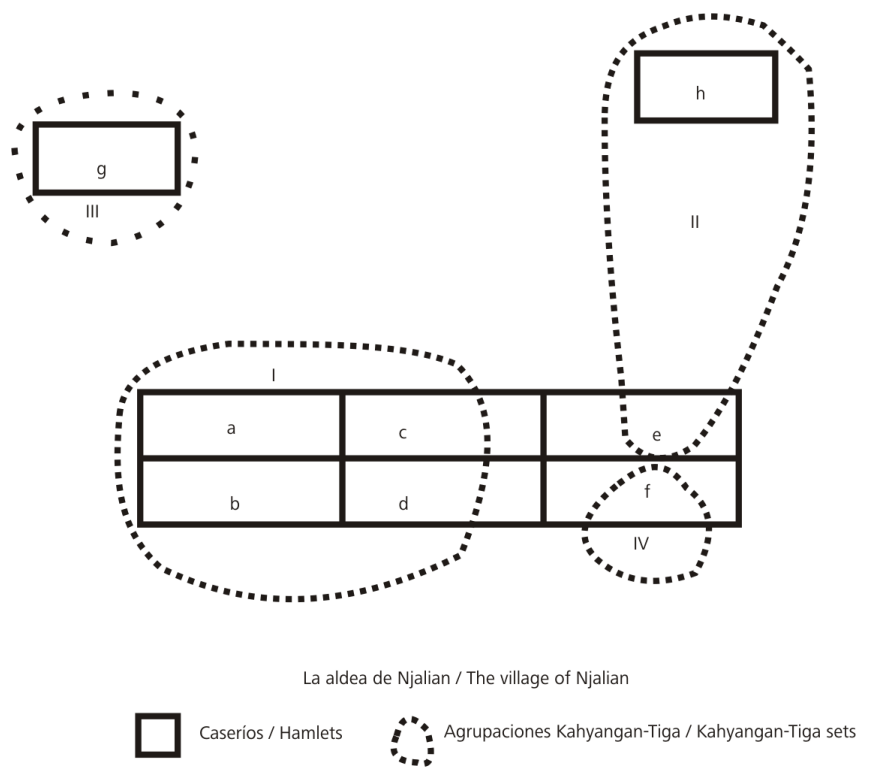

Incluso este diagrama bastante complicado simplifica en exceso la situación. En primer lugar, mucha gente que vive en el territorio de un caserío es legalmente miembro de otra. Luego, la coordinación de los conjuntos de templos con los límites o fronteras del caserío es muy reciente, ya que se instituyó en 1950 tras una fuerte oposición por parte del actual Perbekel, y es aún muy imperfecta. Antes del cambio, un hombre que pertenecía a un caserío "a" a menudo pertenecía también al conjunto de templos IV, o un hombre en "e" pertenecía al conjunto I, y así sucesivamente, y hasta cierto punto esto todavía sigue ocurriendo, ya que las alianzas o lealtades tradicionales son difíciles de reorganizar por decretos administrativos. Aún más, los cuatro bandjar en el conjunto de templos I -"a", "b", "c", y "d"- no son territoriales; aunque las casas de reunión comprendidas se distribuyen conforme al diagrama, los miembros de los caseríos vinculados a ellos se intercalan aleatoriamente por toda el área a-bc-d. Este tipo de organización no territorial del caserío es de hecho frecuente en Bali aunque no se ha tenido en cuenta en el diagrama por propósitos de simplicidad descriptiva. Finalmente, en Njalian, la unidad que coopera en una cremación -llamada patus- no es coincidente con el caserío como suele ser en los otros lugares. En cambio, el caserío "a" se divide en dos grupos de trabajo colectivo para las cremaciones, "b" forma un patus, " $c$ " dos, y así sucesivamente. De este modo un hombre puede tener su alianza de caserío en un lugar (ni siquiera necesariamente en la que vive), sus lazos de templo en un segundo lugar, y sus obligaciones para las cremaciones en un tercer lugar, aunque por supuesto en la mayoría de los casos algunas de estas afiliaciones pueden fusionarse. 
Desde que Njalian contiene representantes de una amplia gama de títulos de casta, la interacción de la jerarquía de estatus con el caserío y el sistema de templos añade aún otra dimensión de complejidad. El caserío "a" integra Brahmana y Satria superiores, incluyendo la familia gobernante, pero algunos Triwangsa pertenecen a " $b$ ", "c", " d", y "e", mezclados entre los Sudra. Los caseríos "f", " $g$ " y " $h$ " son Sudra en su totalidad, con " $f$ " que consiste en un grupo de parentesco dadia, algo poco común. La casta afecta también a la organización del templo. En el conjunto de templos I, el templo de los muertos estaba, hasta hace dos años, dividido por un muro bajo, los Sudra organizaban su festejo por separado y lo celebraban en un lado del muro, los Triwangsa celebraban el suyo en el otro. Sin embargo, esta situación cambió por razones de economía y democracia, y actualmente rinden culto todos juntos. Las organizaciones voluntarias -unas docenas-, las sociedades de riego,-dos principales en esta área-, y cerca de treinta o cuarenta grupos de parentesco también complican las relaciones sociales, aunque el parentesco como fuerza organizativa es evidentemente menos importante aquí que en muchas otras aldeas.

En tal caso, ciertamente extremo, de agrupamientos sociales transversales, el problema de integración y adaptación mutua entre los grupos es apremiante. A veces las peleas abiertas se desatan entre los líderes de varios grupos con relación a quién tenía los derechos prioritarios en los servicios de los miembros comunes a ellos. Afrontar demasiadas exigencias concurrentes puede implicar que se cumpla con el trabajo apresuradamente; cuando se toca el gong para llamar a los miembros de un determinado grupo, muchos no concurren por encontrarse lejos y no haber escuchado el llamado o por creer que el llamado apelaba a otro grupo. A los efectos de racionalizar esta situación, el Perbekel instituyó una reunión mensual que convoca a todos los líderes de los grupos importantes -alrededor de cincuenta personasen la cual, con valentía, intenta que los líderes logren coordinar sus variados esfuerzos. También intenta lograr mayor territorialización del sistema al basar la pertenencia del caserío y del templo en la residencia; sin embargo, los aldeanos se resisten a esto ya que, según él, prefieren que las cosas no se simplifiquen. Pese a que el Perbekel es el jefe tradicional del área, que lo ha sido por treinta años, y que ahora tiene todo el estado indonesio detrás de él, sostiene que es realmente poco lo que puede hacer para reformar las instituciones de la aldea. Las personas se comportan servilmente, pero solo lo hacen como ellos desean.

\section{Tihingan}

Pese a encontrarse a unos diez kilómetros al este de Njalian, en el corazón del antiguo reino de Klungkung, Tihingan difiere de Njalian en la mayoría de sus características o aspectos importantes. A diferencia de Njalian, Tihingan nunca ha sido la sede de un señor; tiene relativamente pocos Triwangsa; y el Perbekel es un Sudra. A diferencia de Njalian, las afiliaciones sociales, aunque complejamente organizadas, se integran sistemáticamente en lugar de ser transversalmente aleatorias. Y a diferencia de Njalian, existen, entre los Perbekelan, tres agrupaciones espaciales bien definidas de lealtad social a las cuales el nombre de la aldea puede aplicarse correctamente, mientras que el perbekelan, en su totalidad, forma la unidad social menos definida. Se trata entonces de Pau, Penasan y Tihingan (la sede del Perbekel que, en consecuencia, presta su nombre a todo el perbekelan). Nos ocuparemos aquí de Tihingan.

Tihingan consiste de un caserío de unas 138 cocinas agrupadas en 85 casas-recintos, y no hay más que un conjunto de templos Kahyangan-Tiga al cual todos los miembros del caserío pertenecen, una agrupación atípica por su simplicidad. Hay un sacerdote Brahmana que vive en la aldea, y hay una dispersión de familias Satria y Vesia con títulos nobiliarios no tan importantes; no obstante cerca del noventa por ciento de la población es Sudra. Desde el punto de vista estructural, sin embargo, la característica más notable de Tihingan no reside en su patrón territorial o en su sistema de estatus, sino en la ciertamente inusual importancia que se le asigna al parentesco como fuerza organizacional en la vida social. Se trata de las cuatro dadia, que representan casi el ochenta por ciento de la población de la aldea, y forman el eje alrededor del cual se centra la vida en la aldea de Tihingan; y las implicancias de este simple hecho pueden hallarse en todos los niveles de su organización social. En el plano religioso, cada dadia mayor posee un importante templo, magníficamente tallado (en el caso de las dos dadia más importantes el templo es inclusive más grande y más elegantemente tallado que los templos KahyanganTiga teóricamente superiores) cerca del centro de la aldea. El mantenimiento de este templo y la adecuada realización de las ceremonias semianuales forman parte de las principales funciones de la dadia; en función de esto pueden desatarse rivalidades particularmente intensas.

En el plano político, la distribución de los roles de liderazgo del caserío se planea consciente y cuidadosamente a fin de representar fielmente el equilibrio de poder dadia. Hay cinco klian o jefes. Cuatro son elegidos, uno por cada dadia principal; el quinto klian al mismo tiempo asume el cargo de Pengliman y es miembro de la segunda dadia más grande. Desde el momento mismo en que el Perbekel, hombre con cierto peso dentro de Tihingan, se conforma como miembro de la dadia principal, la fundación del grupo de parentesco para lograr el liderazgo local es clara y precisa. Además, en los procesos políticos supraaldea, institucionalizados en el sistema de partidos de la "Nueva Indonesia", los dos grupos de parentesco mayores se asocian como facción en contra de los dos grupos que le siguen, además de todas las familias que no pertenecen a alguna dadia. El primer grupo pertenece al partido Socialista y el segundo al Nacionalista, por lo que la alianza entre partidos es absolutamente predecible a 
partir de la pertenencia a grupos de parentesco, y refleja, asimismo, la organización interna de la aldea más que la convicción ideológica personal.

En el plano económico, cada dadia forma un grupo de trabajo cooperativo para la fabricación de instrumentos musicales balineses -metalófonos, gongs, platillos, etc-, una artesanía de herrería en la cual esta aldea está parcialmente especializada; el personal que trabaja en cualquier herrería es miembro, casi inevitablemente, de la misma dadia. ${ }^{10}$ Además, la mayoría de los patrones de tenencia y trabajo de intercambio en los cultivos de arroz también siguen las líneas de los grupos de parentesco, introduciendo estas alianzas al contexto de la sociedad de riego. Las relaciones económicas más informales -préstamo de dinero, clientela, etc- siguen el mismo patrón.

Finalmente, incluso la interacción recreativa informal se ve moldeada por lazos de parentesco extendidos. Rara vez un hombre entra, después del anochecer, a la casa-recinto de otro sin estar emparentado, momento en el cual tienen lugar los chismes más intensos, pero sí se moverá libremente entre los patios de los miembros de su dadia (en Tihingan una adhesión al ideal virilocal un poco más consistente y literal que lo usual en otros lugares significa que las casas compuestas de las mismas dadia tienden a estar bastante bien agrupadas dentro del caserío). En la riña de gallos, gran parte del patrón de alianza y oposición -quién riña con quién, quién gana la apuesta contra quién- se explica únicamente en términos de parentesco. En la religión, la política, la economía y la interacción social informal, la pertenencia al grupo de parentesco por lo tanto tiene primacía en Tihingan, que, a pesar de que está lejos de representar un patrón universal en Bali, es, como la estructura enrejada de Njalian, un ejemplo realizado de una posibilidad intrínseca en los tipos de intersección de planos de organización de la aldea.

En este tipo de organización de aldea, el riesgo de faccionalismo se torna evidente; se agudiza además el problema de contener las lealtades a los grupos de parentesco dentro de los límites de afiliación en el caserío, en la sociedad de riego, en el grupo de templo, entre otros. Las actividades públicas con frecuencia están selladas por el antagonismo, parcialmente visible, entre grupos de parentesco. Por ejemplo, hace diez años, cuando el sacerdote heredero de los templos del origen y templos de la muerte falleció sin dejar heredero, los grupos de parentesco no pudieron acordar su sucesor, por lo que la responsabilidad en torno a las ceremonias en estos templos ahora se rota entre los sacerdotes de los cuatro templos de la dadia -un patrón altamente insatisfactorio

\footnotetext{
10 La especialización económica por aldea aún persiste en algún grado en Bali, y es otro factor a considerar para un análisis completo de la variación en la estructura de la aldea balinesa. Se ha ignorado aquí en favor de consideraciones más formales en aras de la simplicidad.
}

e irregular que los mismos sujetos consideran como "no del todo bien, pero preferible a una guerra abierta"En las reuniones de caserío en el balé, es difícil arribar a un tipo de acuerdo universal; muchas propuestas son bloqueadas por la oposición de un grupo de parentesco minoritario. Por ejemplo, cuando el Perbekel trató de convencer al caserío para cambiar las costumbres funerarias y enterrar a la gente inmediatamente, incluso en un día poco fortuito, antes que guardar el cadáver en la casa por varios días (una reforma de salud sugerida por el gobierno y que el bandjar vecino había adoptado sin resquemor), la oposición de la dadia más hostil al Perbekel impidió que el cambio se llevase a cabo, a pesar de que la mayoría de los habitantes estaban a favor de la propuesta. El antagonismo resultante de matrimonios y divorcios, la rivalidad económica entre los grupos que fabrican instrumentos musicales, y la competencia de prestigio exhibida en las ceremonias en el templo de la dadia también contribuyeron a la agudización de esta especie de tensión intergrupal.

Aun así y en general, la aldea está bastante bien integrada y la faccionalización usualmente se mantiene entre sus límites. ${ }^{11}$ Esto se logra, en parte, por la aplicación concurrente de dos reglas explícitas de procedimiento. La primera regla establece que, toda vez que a un grupo formado sobre la base de un principio de afiliación se le asigna una función social determinada, ningún otro principio de afiliación podrá recibir reconocimiento alguno. Entonces, si el caserío está participando en alguna tarea, el trabajo nunca se suborganiza en términos de parentesco, casta u otro lazo. Si los subgrupos son técnicamente necesarios, las personas son agrupadas de una manera aleatoria y cada familia es considerada como un miembro del caserío puro y simple, sin diferenciarse cualitativamente de las otras ("El caserío no conoce parentesco alguno", dice el proverbio balinés). Del mismo modo, cuando una dadia colabora en la celebración de algún templo, los lazos sub-dadia dentro de la dadia se consideran nulos y no actúan como base de diferenciación entre subgrupos.

La segunda regla establece una jerarquía de prioridad en la que las necesidades del caserío son superiores a las de la dadia, las necesidades de la dadia son superiores a las de la sub-dadia, y las necesidades de las sub-dadia son superiores a las de los grupos voluntarios. Por ejemplo, si el caserío desea cosechar los campos de sus miembros, entonces tiene la prioridad. Todo el bandjar debe cosechar, y debe hacerlo como grupo, sin diferenciación interna. Si el caserío no desea cosechar -por decisión de la reunión de caserío- entonces le sigue a la dadia el derecho a hacerlo, con familias no afiliadas uniéndose o cediéndose sus derechos. Si la dadia también opta por

\footnotetext{
11 La única vez que corrió riesgos de romper esos límites fue durante las elecciones generales de Indonesia, en 1955, donde ambas facciones se armaron en temor de una masacre por parte de la otra, aunque no llegaron a producirse episodios de violencia real.
} 
no cosechar, entonces la sub-dadia puede hacerlo; si la sub-dadia no tiene necesidades inmediatas, entonces se concede la tarea a los grupos voluntarios. La combinación de estas dos reglas de procedimiento - una que prohíbe las bases de afiliación múltiples para una determinada tarea, la otra que establece un orden de prioridad-actúa como un importante mecanismo de integración en esta aldea por lo demás bastante propensa a la facción.

\section{Blaju}

A diferencia de Njalian, Blaju no es el nombre de un perbekelan, y a diferencia de Tihingan, no es el nombre de una unidad de aldea bastante bien definida dentro de un perbekalan. Más bien, es el nombre de una región, definida ampliamente, de unos diez kilómetros cuadrados hacia el extremo oriental del Regente de Tabanan, dentro del cual la influencia de una familia gobernante determinada era preponderante en el período pre-colonial y, en gran medida, continúa en la actualidad. Como tal, Blaju forma un estado minúsculo dentro del estado, y su patrón de organización se caracteriza principalmente por un énfasis en la territorialidad y la casta (o título) como bases de afiliación social. Quizás más que cualquier otra área en Bali, Blaju se aproxima al estereotipo común de la estructura social campesina, organizada en términos de una pirámide de unidades territoriales cada vez más inclusivas -barrios, aldeas, subdistritos, distritos y otroscada unidad gobernada por un funcionario político de estatus apropiado. Pero, desafortunadamente para el tipo de teoría al que le gustaría ver en este sistema una supervivencia del patrón balinés "original" a partir del cual todo lo demás podría ajustarse como "desviación", esta territorialización jerárquica es un fenómeno bastante reciente, que sucede a raíz de una innovación social motivada conscientemente, explícitamente designada para intensificar la integración social.

El área comúnmente denominada como Blaju contiene cuatro perbekelan, tres de ellos contiguos, y uno a un kilómetro hacia el norte. Los miembros de estos cuatro perbekelan -con unas 1500 cocinas - tienen un conjunto común de templos Kahyangan-Tiga, más bien una circunstancia inusual, ya que comúnmente las congregaciones Kahyangan-Tiga son más pequeñas que un perbekelan. Dentro de cada uno de estos perbekelan hay cuatro caseríos y cada caserío se divide en tres a seis subunidades territoriales llamadas kliran. Un kliran posee fronteras establecidas arbitrariamente, y todo adulto que vive entre estas fronteras es, ipso facto, miembro de ese kliran. Es el kliran, con un promedio de dieciocho a veinte cocinas, el que lleva a cabo muchas de las importantes funciones sociales cotidianas, y es la unidad básica de trabajo cooperativo en la siembra, la cosecha, los rituales, entre otros, con su propia tesorería independiente, su arroz y su lugar de reunión. Para las tareas locales más importantes, los kliran de un caserío se fusionan como una sola unidad; del mismo modo en que los caseríos se unen dentro de los perbekelan para los asuntos de gobierno, y los perbekelan se unen dentro de Blaju para mantener los templos Kahyangan-Tiga. Como las sociedades de riego en el área de Blaju son pequeñas y la tenencia de la tierra no es tan dispersa, las sociedades de riego tienden a identificarse informalmente con el perbekelan y los caseríos cercanos, es por ello que el sistema se territorializa por completo.

En el centro geográfico de este conjunto territorial complejo, frente al mercado y al principal cruce, se encuentra el "palacio" (puri) de la familia gobernante, un complejo amurallado y venido abajo de casas, patios, callejones, del tamaño de una cuadra, abarrotado de más de quinientas personas que conforman una sola dadia de nivel Vesia. La cabeza de esta dadia, Anak Agung Ngurah Njoman, es, paralelamente, el jefe de ley habitual para toda el área de Blaju -es decir, para los cuatro perbekelan dentro del conjunto de Kahyangan-Tiga. Aunque en gran parte representa un cargo honorario destinado a asesorar y dar consejos en materia de tradición, este rol apical simboliza el continuo dominio de la familia gobernante en la zona. En el nivel de perbekelan, dos de los cuatro perberkel pertenecen a esta familia (uno de ellos el mismo Anak Agung), los otros dos son de nivel Sudra con vínculos tradicionales para con el "castillo".

La función de este grupo de elite se fortalece en muchos sentidos. Primero, a diferencia de muchos aristócratas balineses, la familia gobernante de Blaju no se empobrece. Alrededor de una quinta parte de todo el arrozal en el área se encuentra, todavía, bajo su dominio (aunque es de propiedad individual, no colectiva, entre la dadia), y como casi toda esta tierra está arrendada por Sudra quienes también tienen obligaciones de prestación personal con sus terratenientes, los vínculos tradicionales entre patróndependiente mantienen importancia integrativa central. Segundo, aunque los miembros de la dadia gobernante viven todos en un solo lugar y por lo tanto deberían ser miembros de un solo caserío conforme al sistema territorial, son, por práctica tradicional, distribuidos entre los dieciséis bandjar en grupos más o menos equitativos. Se les asigna una pertenencia bandjar sin importar su residencia, con el fin de asegurar una voz (y un oído) en la casa gobernante de cada localidad, y para fortalecer la unidad de toda la región. Tercero, en Blaju encontramos un templo mayor, disputándose con el Kahyangan-Tiga la mayor importancia, que es mantenido exclusivamente por toda la gente de la región que porta Triwangsa, títulos de casta superior, simbolizando así la importancia del estatus y de utilidad para aliar, con la dadia gobernante, a todos los grupos locales de alto prestigio en un exitoso esfuerzo por mantener inalterado el sistema de estratificación tradicional.

Como se ha señalado, esta integración ordenada del territorialismo y el estatus no es una cuestión del todo tradicional, pero se debe, en parte, a las reformas recientes. El patrón kliran del sub-caserío, el elemento 
distintivo de todo el sistema, fue instituido recién en 1940. En este momento el sistema de caserío era bastante débil, el parentesco no era importante, y la mayoría de las funciones de la aldea había recaído en las manos de los grupos voluntarios seka. "La gente" sintió - evidentemente bajo la insistencia de la aristocracia, que comenzó a reafirmar su liderazgo en ese momento- que había demasiados de esos grupos, formados para el conflicto y para la disminución de valiosas actividades públicas, y dio lugar a un tipo de individualismo. "Los seka se hicieron ricos, pero los bandjar se hicieron pobres". Así los dieciséis caseríos decidieron conjuntamente instituir el sistema kliran y prohibir el funcionamiento de las organizaciones voluntarias para todas las funciones importantes. Y cuando los holandeses se fueron en 1941, la familia gobernante intensificó sus esfuerzos para fortalecer el sistema de estatus que también había sido debilitado durante ese movimiento hacia una sociedad menos orgánica; se produjo como resultado el patrón de organización actual. Por consiguiente, el territorialismo en Blaju no es una simple supervivencia de un pasado remoto, sino el resultado de la interacción entre los valores tradicionales y los eventos poco tradicionales del siglo veinte.

En este sistema es probable que las tensiones integradoras aparezcan en todas las castas, y a pesar de todas las reverencias que uno ve en Blaju, el resentimiento de los Sudra para con la dominación Triwangsa es bastante evidente. Cuando una dadia Sudra pequeña de Sunguhu, que tradicionalmente tiene el derecho de patrocinar a los sacerdotes designados de entre sus propios miembros y no entre los Brahmana, intentó institucionalizar este sistema en Blaju hace unos años, fueron expulsados de su caserío bajo presión de los Triwangsa por "injuriar la costumbre local y denigrar a las castas superiores". A pesar de las presiones por parte de la burocracia central y de cierta simpatía local por los rebeldes, las castas superiores de Blaju se mantuvieron firmes y los Sunguhu finalmente capitularon. Sin embargo, independientemente de tales tensiones, Blaju evidencia mayor cohesión que la mayoría de las aldeas balinesas: las 1500 familias eran miembros de un solo partido político nacional, y una de las pocas cooperativas consumidor-productor realmente efectivas en Bali se estableció en Blaju, y su eficacia deriva principalmente del hecho de que la misma tenía ciento por ciento de pertenencia.

\section{ALGUNAS IMPLICANCIAS TEÓRICAS}

De los numerosos problemas teóricos que surgen del análisis de la organización de la aldea balinesa, los más interesantes son aquellos que se centran en cuestiones de tipología. La tipologización siempre ha sido una preocupación central de la antropología social porque ambas, la simplicidad descriptiva y la generalización comparativa, descansan en la posibilidad de sintetizar a las organizaciones sociales simultáneamente en términos de constructos etnográficamente circunstanciales y formalmente distintivos. Cualesquiera sean sus limitaciones en relación con las perspectivas teóricas más sofisticadas, como "La Aldea Hindú", "El Estado Chino" o "El Sistema de Parentesco Nuer" (para no mencionar la "Sociedad Campesina" o la "Organización Social Segmentaria", que son quizás mejor vistas como tipos de segundo orden) parecen fundamentales para un análisis comparativo, aunque sea rudimentario. Sin embargo, el caso balinés, en el cual la tarea metodológica fundamental de separar la madera del bosque parece extraordinariamente difícil, sugiere que algunos de los supuestos que subyacen en nuestros procedimientos usuales de tipologización pueden necesitar revisión. Particularmente, y quizás paradójicamente, sugieren que los indicios que revelan lo tipológicamente esencial pueden depender de fenómenos raros o únicos al igual que de fenómenos comunes o típicos; sugieren además que esa forma esencial puede contemplarse más adecuadamente en términos de un rango de variación que en términos de un patrón fijo a partir del cual surgen los casos desviados.

En antropología, encontramos por lo general dos aproximaciones principales que abordan el problema de construir tipologías de organización social de primer orden, en un área cultural determinada: el enfoque del "mínimo común denominador" y el enfoque de la "unidad representativa". En el primero, el procedimiento consiste en crear una imagen sintética de "La Vida Esquimal", o "La cultura Oral", o "La Sociedad China", adoptando las variadas formas que se encuentran en la mayor parte de las respectivas áreas culturales e integrándolas a fin de proporcionar, en un sentido general, un informe generalizado de la estructura social. Aquí el antropólogo se concentra en identificar lo que es típico de aquello que no lo es, dentro del campo social. Como resultado se obtendrá una imagen que describa directamente no a una unidad social real particular, sino a una síntesis de la forma social característica de tal sociedad, en función de cualquier aspecto que uno desee observar. Desde tal perspectiva, las variaciones se interpretan como desviaciones del patrón general, causadas por fuerzas de naturaleza ecológica, histórica o aculturativa, que actúan a nivel local. Este es el enfoque más antiguo y popular. Es el que adoptan los libros de textos y las monografías descriptivas, los volúmenes del tipo Our Primitive Contemporaries de Murdock (1934), y en su mayor parte, los antropólogos británicos africanistas.

El enfoque de "la unidad representativa" podría denominarse "Middletown", ya que su procedimiento consiste en elegir una comunidad concreta -aldea, pueblo o asentamiento tribal - que es, en sentido amplio, "típica" o representativa del tipo de comunidad que puede hallarse en un área cultural. Independientemente de si la decisión surge a partir de un estudio social y cultural sistemático de toda el área, o surge de manera más intuitiva, los 
esfuerzos se centran en encontrar una comunidad que constituya una muestra útil de la sociedad en general, una en la que los rasgos idiosincráticos sean pocos en relación con aquellos que comparten las comunidades, y una en la que la mayoría de los patrones considerados básicos en la sociedad logre representar de manera "normal". Este procedimiento puede perfeccionarse al elegir varias de estas comunidades, circunscriptas a áreas subculturales, como en el estudio de Puerto Rico llevado a cabo por Steward (Steward et al. 1956); aún así, la estrategia metodológica sigue siendo la misma: es decir, tomar una comunidad que sea lo más representativa posible de una sociedad mayor. ${ }^{12}$

Ambos procedimientos arrojan resultados más bien extraños cuando se los implementa en Bali. El enfoque del mínimo común denominador obviamente depende de la posibilidad de encontrar patrones fundamentales, simples -una aldea territorial, un sistema de linaje y clan, una estructura de casta desarrollada-, que se reiteren, de modo muy similar, en varias partes del área cultural. Pero en Bali, si bien encontramos patrones comunes a toda el área, su forma difiere tanto que toda imagen sintética que pretenda representar patrones comunes perderá su esencia por ser demasiado generalizada. Uno podría fácilmente construir una "aldea balinesa" con un establecimiento "típico" de templos, una organización "típica" del caserío, del sistema de parentesco, de la sociedad de riego, de la distribución de títulos y otros elementos. Pero tal construcción dejaría de expresar las dos características más fundamentales de la organización de la aldea balinesa, a saber, que estos patrones se diferencian ampliamente de aldea a aldea, y que su relativa importancia varía en la integración de cualquier aldea en particular. Por razones similares, el enfoque de la unidad representativa inducirá, casi certeramente, a error. ¿Optamos por considerar a Njalian, Tihingan o Blaju como típicas de Bali? Desde un plano descriptivo directo, dejan de ser típicas o representativas cuando traspasan sus propias fronteras; y probablemente tampoco lo sea cualquier otra aldea balinesa. Si vamos a discriminar lo que es realmente esencial y característico en la organización de la aldea balinesa, necesitamos tomar un rumbo diferente y conceptualizar esa organización ya no en términos de invariancia en la estructura a lo largo de la

12 Hay una tercera aproximación tipológica, que es particularmente prevalente en los estudios holandeses sobre Bali (Korn 1936), en la cual una comunidad es elegida para su estudio no tanto sobre las bases de su representatividad en un sentido estadístico, sino más bien porque muestra formas y patrones prototípicos de una manera relativamente poco complicada, directa y no distorsionada. Comunidades altamente tradicionalizadas, que han sido relativamente aisladas de contactos aculturativos, se consideran que han cambiado más lentamente que otras comunidades y por ello son favorecidas al proveer imágenes de las estructuras sociales subyacentes que se opacaron por elementos fortuitos en las comunidades más dinámicas. Este enfoque ha ido perdiendo valor a medida que se ha hecho evidente que está basado en una teoría dudosa sobre el cambio social y que el tradicionalismo de las comunidades aisladas es a menudo interpretable tanto como una adaptación a circunstancias ambientales particulares como a su persistencia a patrones más tempranos y fundamentales. isla, o de sus poblaciones, sino más bien en términos del rango de la estructura que es posible generar a partir de un conjunto establecido de componentes elementales. La forma, desde este punto de vista, no es una constante fundamental en medio de variaciones fortuitas, sino más bien un conjunto de límites dentro del cual yace la variación.

Lo que tienen en común Njalian, Tihingan y Blaju, y las aldeas balinesas en general, es el conjunto de planos de organización social a partir del cual estas se construyen; también el hecho de que todas se realizan con los mismos materiales, aunque en diferentes maneras, lo que hace que se parezcan, pese a la gran diversidad estructural. En la investigación de la organización de la aldea balinesa, uno, sin dudas, procede de manera diametralmente opuesta a la lógica de presentación que se adopta en este trabajo: es decir, los planos se generan a raíz de una inspección de varias aldeas en lugar de analizar formas puras, combinarlas y luego delinear las aldeas. Cuantas más aldeas se analicen, más rápido se pondrá en evidencia el conjunto relativamente pequeño de elementos básicos que las componen; una vez que se han discriminado las unidades de templos, los caseríos, las sociedades de riego, la jerarquía de títulos, el sistema de parentesco, las organizaciones voluntarias y las unidades gubernamentales, puede pensarse que ya es improbable encontrar una aldea que carezca de alguno de estos elementos, o encontrar un plano completamente diferente. ${ }^{13}$ Si bien se pueden identificar con facilidad el número y tipo de elementos utilizado, son sus formas y las posibilidades de ensamble entre sí las que no pueden detectarse fácilmente. Prácticamente todas las aldeas estudiadas revelan alguna organización potencialmente diferente con respecto a uno o varios planos, y un modo de integración también disímil. El proceso de investigación de la organización de la aldea balinesa, en un sentido tipológico, implica un proceso de delimitación progresiva de las posibilidades estructurales inherentes a una serie de elementos sociales fundamentales. Lo que uno encuentra no es una aldea típica ya sea en función del mínimo común denominador, o en función de la unidad representativa, sino un espacio social diferenciado y multidimensional dentro del cual se distribuye la organización de las aldeas balinesas. Uno va descubriendo progresivamente las variadas formas que puede tener una aldea, y aun así no dejar de caracterizarla como balinesa.

Entre otras cosas, esto significa que lo peculiar, lo único y lo extraño adquieren un significado diferente al de los procedimientos de tipologización usuales, ya

13 Existe un puñado de las llamadas aldeas Bali Aga ("balinesa original") cuya organización difiere marcadamente de aquellas de la abrumadora mayoría, que tienen grupos de edad, estructura políticas gerontológicas, tenencia comunal de la tierra, etc. Aunque el significado de estas aldeas desde un enfoque etnohistórico es un problema interesante, su posición dentro la sociedad balinesa generalmente es en extremo marginal. Para descripciones de estas aldeas, ver Bukian (1936), Korn (1933), y Bateson y Mead (1942). 
que no se los considera como excepciones a una regla general atribuibles a consideraciones ad hoc, sino que se los contempla como una valiosa aclaración sobre los principios básicos de la organización social. De la estructura transversal de Njalian aprendemos que los varios planos que la componen son, en gran parte, independientes entre sí; de Tihingan conocemos cómo funciona el sistema de parentesco balinés cuando se le da rienda suelta, y cómo los otros planos se adaptan a su dominio; de Blaju comprendemos lo que un mayor territorialismo y un mayor énfasis en el sistema de castas implican para la integración social. Cada caso revela algo nuevo sobre las potencialidades implícitas del modelo tipológico que construimos; establece nuevos límites en su rango de variación; y lo hace principalmente no en términos de lo que es común, sino más bien de lo que es inusual. Del mismo modo en que a Cromwell se lo ha reconocido como el típico inglés de su época, simplemente por ser el más raro, el significado tipológico general de cualquier aldea balinesa reside, principalmente, en su idiosincrasia.

\section{REFERENCIAS CITADAS}

Bateson, G., y M. Mead, 1942, Balinese character: A photographic analysis. New York: New York Academy of Sciences.

Belo, J., 1953, Bali: Temple festival. Monographs of the American Ethnological Society, XXII, Locust Valley, New York.

Bukian, I Dewa Putu,1936, Kajoe Bihi, Een Oud-Balische Bergdesa, bewerkt dor C. J. Grader. Tijdschrift v.d. Bataavische Genootschaap, LXXVI.

Covarrubias, M., 1936, Island of Bali. New York: Alfred A. Knopf.

Korn, V. E., 1933, De Dorpsrepubliek Tnganan Pagringsingan, Kirtya Liefrinck van der Tuuk. Singaradja, Bali.

Murdock, G. P., 1934, Our primitive contemporaries. New York: Macmillan.

Raka, I Gusti Gde, 1955, Monographi Pulau Bali. Djakarta: Indonesian Republic, Ministry of Agriculture.

Steward, J., et al., 1956, The people of Puerto Rico. Urbana: University of Illinois Press. 